\title{
Coordination $\left[\mathrm{CO}_{2}\right]$ and $[\mathrm{Co} " \mathrm{Zn}]$ helicates showing slow magnetic re- laxation
}

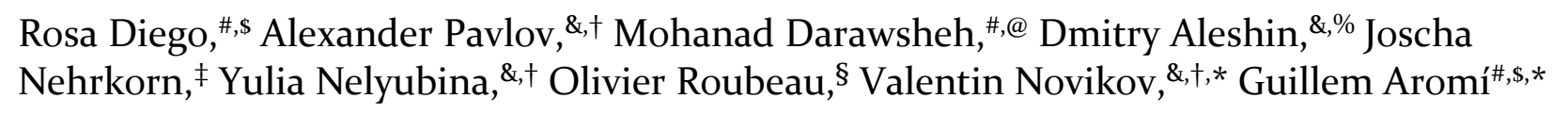

\# Departament de Química Inorgànica i Orgànica, Universitat de Barcelona, Diagonal 645, o8028 Barcelona, Spain

${ }^{s}$ Institute of Nanoscience and Nanotechnology of the Univesity of Barcelona (IN2UB), Barcelona, Spain.

\& A. N. Nesmeyanov Institute of Organoelement Compounds, Russian Academy of Sciences, Vavilova str. 28, Moscow, Russia

${ }^{\dagger}$ Moscow Institute of Physics and Technology, Institutskiy per., 9, Dolgoprudny, Moscow Region, Russia

${ }^{\%}$ Mendeleev University of Chemical Technology of Russia, Miusskaya sq., 9, 125047 Moscow, Russia

‡ Max Planck Institute for Chemical Energy Conversion, Stiftstr. 34-36, 45470 Mülheim an der Ruhr, Germany

$\S$ Instituto de Ciencia de Materiales de Aragón (ICMA), CSIC and Universidad de Zaragoza, Pedro Cerbuna 12, 50009, Zaragoza, Spain.

KEYWORDS (Word Style "BG_Keywords"). Single molecule magnet, coordination helicate, paramagnetic NMR, cobalt, magnetic susceptibility, magnetic anisotropy.

Supporting Information Placeholder

\begin{abstract}
The slow magnetic relaxation of Co(II) in the elusive intermediate geometry between trigonal prism and trigonal antiprism has been studied on the new $\left[\mathrm{Co}_{2} \mathrm{~L}_{3}\right]^{4^{+}}$and $\left[\mathrm{CoZnL}_{3}\right]^{4^{+}}$coordination helicates $(\mathrm{L}$ is a bispyrazolylpyridine ligand). Solution paramagnetic ${ }^{1} \mathrm{H}-\mathrm{NMR}$ and solid-state magnetization measurements unveil singlemolecule magnet behavior with small axial anisotropy, as predicted previously.
\end{abstract}

Controlling the magnetic states of certain molecules, the socalled single-molecule magnets, $\mathrm{SMMs},{ }^{1-4}$ opens wide possibilities for creating new devices for ultrahigh-density information storage..$^{-6}$ SMMs are paramagnetic $d$ - or $f$-metal complexes with large magnetic anisotropy, resulting in slow magnetic relaxation of the magnetic moment..$^{7-14}$ Among first row transition metal SMMs, cobalt complexes have the largest barrier of magnetization reversal, ${ }^{15-18}$ which in the case of a two-coordinate linear cobalt(II) complex ${ }^{19}$ approaches the theoretical limit in that environment of $450 \mathrm{~cm}^{-1}$. These complexes and their cobalt(I), ${ }^{20}$ iron(I $)^{21}$ and iron(II) ${ }^{22}$ analogues are, however, unstable, making any possible technological applications extremely challenging.

Among other coordination environments that also ensure large magnetic anisotropy of cobalt(II) while keeping the complex chemically stable, a trigonal prism (TP) recently emerged as an ideal geometry. ${ }^{17},{ }^{23}$ Despite some recent examples acting as SMMs, ${ }^{18,24-25}$ these compounds remain unusual, as the TP geometry is limited to rather exotic rigid clathrochelate ligands. ${ }^{26}$ More common scorpionate-like ligands often lead to trigonal antiprism (TAP) geometries, ${ }^{27}$ where slow relaxation is only observed under an applied magnetic field. ${ }^{28-30} \mathrm{~A}$ distortion from a TP towards a TAP geometry (Bailar twist) reduces further the SMM performance with respect to both ideal polyhedra. ${ }^{31}$ It was even predicted $3^{2}$ that at an angle $\varphi$ of ca. $40^{\circ}\left(\varphi=0^{\circ}\right.$ and $\varphi=60^{\circ}$ for ideal TP and TAP, respectively) the axial parameter, $D$, of the zero field splitting (ZFS) changes its sign; however, no experimental data on the SMM behavior have been collected for the cobalt(II) complexes with trigonal symmetry and $\varphi$ between 24 and $57^{\circ}$, which should provide a better understanding of magneto-structural correlations for cobalt(II)based SMMs.

We have synthesized a new cobalt(II) dinuclear helicate from a new bis(pyrazolylpyridine) ligand (L, 1,3-bis[1-(pyridine-2yl)-pyrazol-3-yl]benzene), 33 which ensures trigonal geometry, intermediate between the TP and the TAP, around the metal ion. Indeed, the analogous helicates with $\mathrm{Fe}(\mathrm{II})$ feature $\varphi \approx$ 30.33-34 Besides the desired coordination geometry, this helicate exhibits two metal centers, which might modulate the SMM properties of the corresponding cobalt(II) ions by exchange bias. ${ }^{35}$ We have employed this compound to study the magnetic relaxation of $\mathrm{Co}(\mathrm{II})$ in this elusive intermediate geometry. To analyze the mutual effect of the Co(II) ions within the $\left[\mathbf{C o}_{2}\right]$ molecule, we have also prepared the mixed metal [CoZn] helicate, as part of a solid solution with the homometallic analogue; $\left[\mathbf{Z n}_{\mathbf{2}}\right]$. For comparison and for further support, the pure $\left[\mathbf{Z} \mathbf{n}_{\mathbf{2}}\right]$ has been prepared and characterized. 


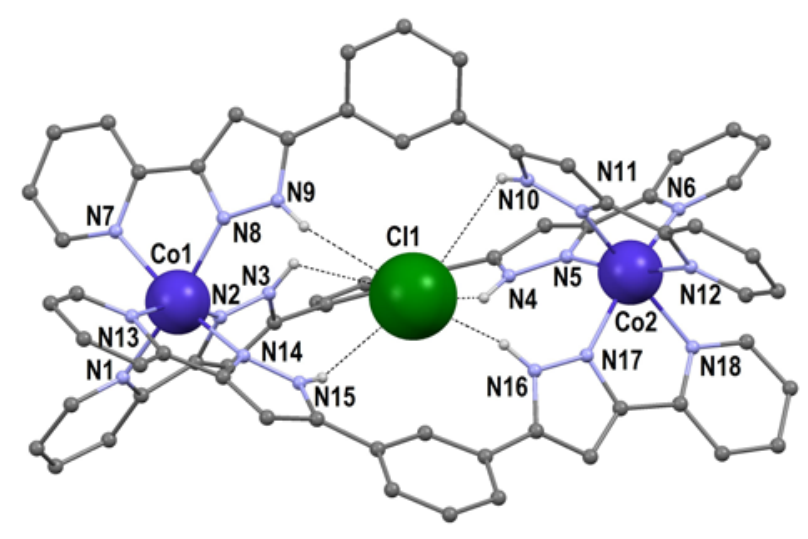

Figure 1. Molecular structure of $\left(\mathrm{Cl} @\left[\mathrm{Co}_{2} \mathrm{~L}_{3}\right]\right)^{3^{+}}$in 1. Only heteroatoms are labelled, with $\mathrm{C}$ and $\mathrm{H}$ shown in dark and light grey, respectively. Only $\mathrm{H}$ atoms that are part $\mathrm{H}$-bonds (dashed lines) are shown.

The triple stranded $\left[\mathbf{C o}_{2}\right]$ helicate, with formula $\mathrm{Cl} @\left[\mathrm{Co}_{2} \mathrm{~L}_{3}\right] \mathrm{Cl}\left(\mathrm{PF}_{6}\right)_{2}(\mathbf{1})$, has one of its four anions encapsulated as a $\mathrm{Cl}^{-}$species inside its cavity (see below). Since the helical structure has never been isolated without of $\mathrm{a} \mathrm{Cl}^{-}$or a $\mathrm{Br}^{-}$guest, it is likely that the latter acts as a stabilizing template. Empty specimens have been only detected via mass spectrometry (MS). Complex 1 forms as orange crystals after mixing stoichiometric amounts of $\mathrm{CoCl}_{2} \cdot 6 \mathrm{H}_{2} \mathrm{O}$ and $\mathrm{L}$ in $\mathrm{MeOH}$, with two equivalents of $\mathrm{NBu}_{4} \mathrm{PF}_{6}$, followed by the slow diffusion of diethylether. The analogous procedure using $\mathrm{ZnCl}_{2}$ produces $\mathrm{Cl} @\left[\mathrm{Zn}_{2} \mathrm{~L}_{3}\right] \mathrm{Cl}\left(\mathrm{PF}_{6}\right)_{2}$ (2) as colorless crystals. The yield of $\mathbf{2}$ is poorer than $\mathbf{1}$, presumably due to its higher solubility.

Crystals of both compounds were suitable for single-crystal X-ray diffraction (SCXRD, see below). To obtain the heterometallic [CoZn] analogue, the same synthesis was repeated using an equimolar mixture of the $\mathrm{Co}$ and the $\mathrm{Zn}$ salts. The MS of the resulting orange crystals revealed only the presence of $\left[\mathbf{C o}_{2}\right]$, suggesting a higher propensity of the latter to crystallize over that of any zinc analogue and/or a higher stability in the MS conditions. To force the detection of the [CoZn] species, the reaction was performed with Co and $\mathrm{Zn}$ in the 1:9 ratio. The MS of the resulting pale orange crystals unveiled the presence of the $\left[\mathbf{Z n}_{\mathbf{2}}\right]$ and $[\mathbf{C o Z n}]$ helicates while $\left[\mathbf{C o}_{2}\right]$ was detected in a smaller amount. This is consistent with metal analysis and SCXRD (see below), which suggest the formulation $\left(\mathrm{Cl} @\left[\mathrm{CoZnL}_{3}\right]\right)_{0.19}\left(\mathrm{Cl} @\left[\mathrm{Zn}_{2} \mathrm{~L}_{3}\right]\right)_{0.31} \mathrm{Cl}\left(\mathrm{PF}_{6}\right)_{2}$ (3) and shows that the system does not favor the segregation into homometallic species. Analysis of ${ }^{1} \mathrm{H}$ NMR data (see below) reveals that the presence of the $\left[\mathbf{C o}_{2}\right]$ species in (3) is in fact marginal, confirming that under the MS conditions, its occurrence is magnified due to a higher stability.

Compounds 1, $\mathbf{2}$ and $\mathbf{3}$ are isostructural if small differences in lattice solvent molecules and crystallographic disorder are not considered, therefore, details will only be provided for $\mathbf{1}$. Complete structural information for all three compounds is collected as Supplementary Material. The space group is the tetragonal $\mathrm{I}_{4} \mathrm{Cd}$. The asymmetric unit of 1 contains one $\left(\mathrm{Cl} @\left[\mathrm{Co}_{2} \mathrm{~L}_{3}\right]\right)^{3^{+}}$species, one $\mathrm{Cl}^{-}$and two $\mathrm{PF}_{6}{ }^{-}$disordered anions, together with four molecules of $\mathrm{MeOH}$ and one partially occupied (0.25\%) molecule of diethylether. The
$\left(\mathrm{Cl} @\left[\mathrm{Co}_{2} \mathrm{~L}_{3}\right]\right)^{3+}$ ensemble (Fig. 1) is a dinuclear triple-stranded helicate comprising a central axis that contains two $\mathrm{Co}(\mathrm{II})$ ions lying 9.771 $\AA$ apart. These metals are held together by three L ligands that chelate them through their two pyrazolylpyridyl moieties, furnishing a chiral, distorted trigonal environment that is intermediate between the TP and the TAP, with a distortion angle, $\varphi$, of about $38^{\circ}$. This angle is close to that for which the sign of the axial zero field splitting (ZFS) parameter, $D$, is expected to change in six coordinate Co(II) (see above). ${ }^{32}$ The chirality around both metals of each molecule is the same, and by symmetry, both possible enantiomers $(\Delta-\Delta$ and $\Lambda-\Lambda)$ are present in equal amounts in the lattice. The three ligands feature a total of six $\mathrm{N}-\mathrm{H}$ moieties from the pyrazolyl groups, pointing towards the interior of its central cavity, perfectly poised to encapsulate the $\mathrm{Cl}^{-}$ guest via six $[\mathrm{N}-\mathrm{H}$... $\mathrm{Cl}]$ hydrogen bonds. The helical ensembles occur approximately in sheets along the $a b$ plane, with the $\mathrm{PF}_{6}{ }^{-}$anions localized in between them (SI). Several $\pi \cdots \pi$ and $\mathrm{C}-\mathrm{H} \cdots \pi$ interactions connect the $\left(\mathrm{Cl} @\left[\mathrm{Co}_{2} \mathrm{~L}_{3}\right]\right)^{3+}$ species within the sheets.

Trigonal symmetry of the $\left(\mathrm{Cl} @\left[\mathrm{Co}_{2} \mathrm{~L}_{3}\right]\right)^{3^{+}}$species also follows from ${ }^{1} \mathrm{H}$ NMR data collected in methanol-d ${ }^{4}$ (Fig. 2a), which is consistent with MS experiments. As expected for an SMM, large paramagnetic shifts are observed. ${ }^{36-37}$ However, while large values of axial anisotropy of the magnetic susceptibility tensor at room temperature is often a sign of SMM behavior, ${ }^{17-18}$ the assembly $\left(\mathrm{Cl} @\left[\mathrm{Co}_{2} \mathrm{~L}_{3}\right]\right)^{3^{+}}$has a very moderate value of $\Delta \chi_{\mathrm{ax}}=0.05 \AA^{3}$ (see SI). This is in contrast with other complexes with both the TP $\left(\Delta \chi_{\mathrm{ax}}=0.26 \AA^{3}\right)^{18}$ and TAP $\left(\Delta \chi_{\mathrm{ax}}=0.21 \AA^{3}\right)^{3^{8}}$ geometries. The possible reasons are either the intermediate TP-TAP geometry of the $\left[\mathbf{C o}_{2}\right]$ assembly or the intramolecular magnetic interaction between both $\mathrm{Co}$ (II) ions. To estimate the contribution of the latter, we examined the heterometallic species $\left(\mathrm{Cl} @\left[\mathrm{CoZnL}_{3}\right]\right)^{3^{+}}$; the nature of its synthesis leads to an admixture calculated on the ${ }^{1} \mathrm{H}$ NMR spectrum of $13 \%$ of the [CoZn] complex and $87 \%$ of the [ $\mathbf{Z n}_{\mathbf{2}}$ ] one, with detection of only trace amounts of the $\left[\mathbf{C o}_{2}\right]$ complex.

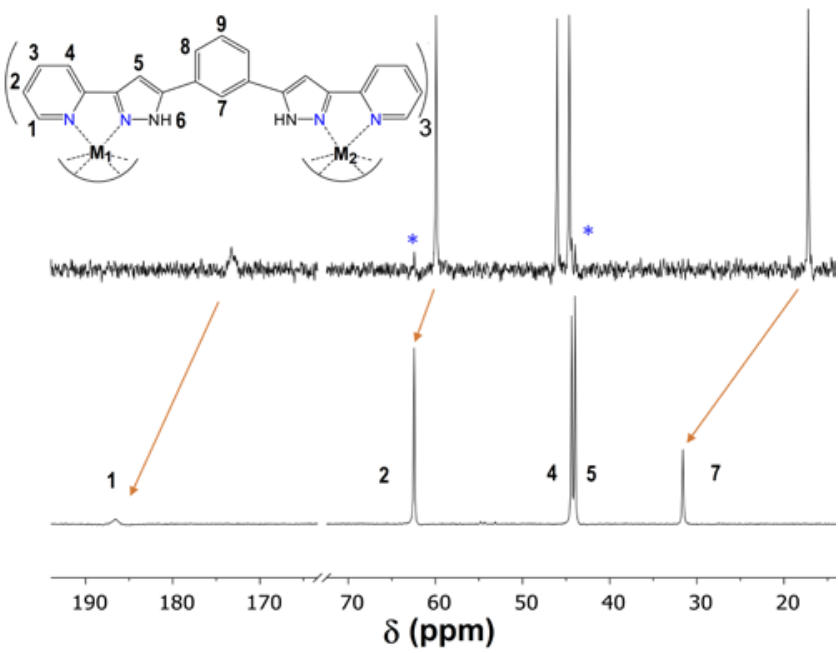

Figure 2. Paramagnetic part of the ${ }^{1} \mathrm{H}$ NMR spectra of $\left(\mathrm{Cl} @\left[\mathrm{Co}_{2} \mathrm{~L}_{3}\right]\right)^{3^{+}}$(bottom) and $\left(\mathrm{Cl} @\left[\mathrm{CoZnL}_{3}\right]\right)^{3^{+}}$(top) in methanol- $\mathrm{d}^{4}$ at $290 \mathrm{~K}$ and their assignment. The signals of $\left(\mathrm{Cl} @\left[\mathrm{Co}_{2} \mathrm{~L}_{3}\right]\right)^{3+}$ not detected in the top spectrum are shown by asterisks. 
The ${ }^{1} \mathrm{H}$ NMR spectrum of the target complex [CoZn] differs significantly from that of the parent $\left[\mathbf{C o}_{2}\right]$ complex. The signals for the protons close to the $\mathrm{Co}(\mathrm{II})$ ion are indeed paramagnetically shifted in a similar manner; however, those close to the zinc(II) ion are not. Moreover, the paramagnetic shift observed for proton 7 (Fig. 2), which is located on the bridging phenyl moiety in between the two metal ions, exhibits a much larger shift in the $\left[\mathbf{C o}_{2}\right]$ complex than in the heterometallic one, where it only feels one cobalt(II) ion. The value of $\Delta \chi_{\text {ax }}$ estimated from the NMR spectrum for [CoZn] $\left(0.05 \AA^{3}\right)$ is virtually the same as the one estimated for the complex $\left[\mathbf{C o}_{2}\right]$. Therefore, the low magnetic anisotropy is not caused by intramolecular magnetic interactions but results from the distorted TP-TAP geometry.

To support these findings from NMR spectroscopy, we turned to dc-magnetometry. Molar magnetic susceptibility $(\chi)$ measured for a fine crystalline sample of 1 at $2-300 \mathrm{~K}$ confirms the Co(II) high-spin state over the entire temperature range (Fig. 3a). At room temperature, the measured $\chi T$ value $\left(5.7 \mathrm{~cm}^{3} \mathrm{~mol}^{-1} \mathrm{~K}\right)$ is larger than the spin-only value for two non-interacting high-spin $\mathrm{Co}(\mathrm{II})$ ions $\left(3.75 \mathrm{~cm}^{3} \mathrm{~mol}^{-1} \mathrm{~K}\right)$, which indicated the influence of spin-orbit coupling. The decrease in $\chi^{T}$ observed upon cooling results also from spinorbit coupling effects. Complex $\left(\mathrm{Cl} @\left[\mathrm{CoZnL}_{3}\right]\right)^{3+}$ shows exactly the same behaviour, after accounting for the dilution by the diamagnetic analog $\left(\mathrm{Cl} @\left[\mathrm{Zn}_{2} \mathrm{~L}_{3}\right]\right)^{3^{+}}$and the presence of only one cobalt(II) ion. This clearly demonstrates the absence of any significant intra- or intermolecular magnetic interactions in the solid state of $\left(\mathrm{Cl} @\left[\mathrm{Co}_{2} \mathrm{~L}_{3}\right]\right)^{3+}$.
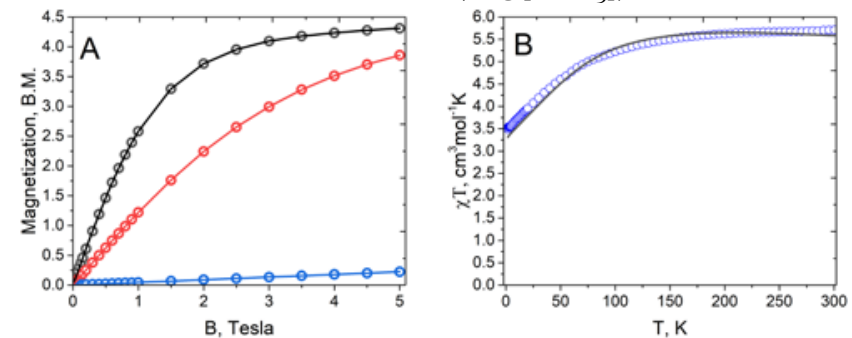

Figure 3. (A) Isothermal magnetization vs. field plots of $\left(\mathrm{Cl} @\left[\mathrm{Co}_{2} \mathrm{~L}_{3}\right]\right)^{3+}$ at $2 \mathrm{~K}$ (black), $5 \mathrm{~K}$ (red) and $100 \mathrm{~K}$ (blue). (B) Variable-temperature magnetic susceptibility under applied d.c. field of $1 \mathrm{kOe}$ (circles). The parameters used to obtain the fits (solid lines) are in Table $\mathrm{S}_{4}$.

By simultaneously fitting the data from dc-magnetometry and temperature-dependent NMR spectroscopy to appropriate Spin Hamiltonians (see SI for details, Table $\mathrm{S}_{5}$ ), we estimated the energy of the first excited magnetic state in $\left(\mathrm{Cl} @\left[\mathrm{Co}_{2} \mathrm{~L}_{3}\right]\right)^{3+}$ to be at least $174 \mathrm{~cm}^{-1}$ (Table S6) and established Ising-type magnetic anisotropy. X-Band EPR was used to shed light into the magnetic structure. ${ }^{39}$ Interestingly, the spectra of $\left(\mathrm{Cl} @\left[\mathrm{Co}_{2} \mathrm{~L}_{3}\right]\right)^{3+}$ and $\left(\mathrm{Cl} @\left[\mathrm{ZnCoL}_{3}\right]\right)^{3+}$ are quite different from those seen in cobalt(II) complexes with a TAP geometry. Instead of well-resolved EPR spectra with a clear axial component, ${ }^{40-42}$ both compounds give the same set of broad lines, indicating a symmetry lower than trigonal and/or as the result of a complicated magnetic behavior (see SI).

To probe the spin dynamics of these complexes, we also performed ac-magnetometry measurements on 1 and 3. In zero magnetic field, no out-of-phase signal was detected even at $2 \mathrm{~K}$. This agrees with a small anisotropy, as expected from an angle $\varphi$ close to $40^{\circ}$. Another explanation could be the presence of fast zero-field tunneling relaxation. Indeed, under a dc field of 100 Oe a signal was observed for both complexes (Figs. S17), revealing slow magnetic relaxation under these conditions.

A fit with the generalized Debye model yielded the field dependence of the relaxation time $\tau$, very similar for both complexes (Fig. 4a); $\tau$ initially increases with the magnetic field and drops sharply at higher fields. The latter is a sign of the direct relaxation mechanism, causing $\tau^{-1}$ to be nearly proportional to $\mathrm{H}^{4}$, as expected for a Kramers system ${ }^{43}$. The small differences between both complexes likely result from larger intermolecular dipolar interactions in $\left[\mathbf{C o}_{2}\right]$.
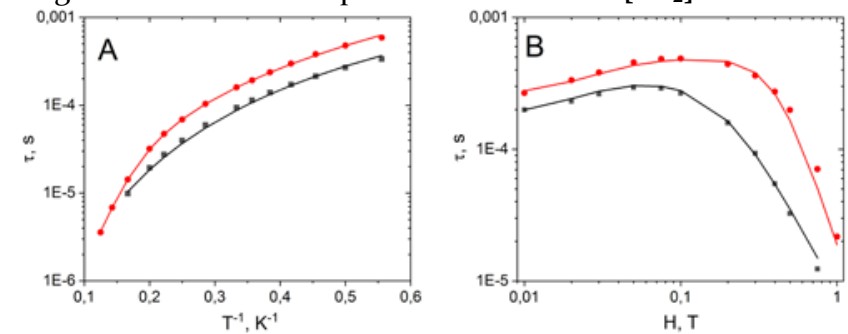

Figure 4. (A) Field dependence of $\tau$ at $2 \mathrm{~K}$ for $\left(\mathrm{Cl} @\left[\mathrm{Co}_{2} \mathrm{~L}_{3}\right]\right)^{3^{+}}$ (black) and $\left(\mathrm{Cl} @\left[\mathrm{CoZnL}_{3}\right]\right)^{3+}$ (red) and (B) its temperature dependence in an optimal field of $1 \mathrm{kOe}$. Parameters used to obtain the fits (solid lines) are collected in Table $\mathrm{S}_{5}$.

Analyses of temperature-dependent ac-data under an optimal field of $1000 \mathrm{Oe}$ (Fig. S18) produced non-linear Arrhenius plots (Fig. 4b) that are again remarkably similar for both complexes. These dependencies can be reproduced invoking quantum tunneling $\left(\mathrm{B}_{1} /\left(1+\mathrm{B}_{2} \mathrm{H}^{2}\right)\right)$, direct $\left(\mathrm{AH}^{\mathrm{n}} \mathrm{T}\right)$, Raman $\left(\mathrm{CT}^{\mathrm{m}}\right)$ and Orbach $\left(\tau_{\mathrm{o}} \exp \left(-\Delta / \mathrm{k}_{\mathrm{B}} \mathrm{T}\right)\right)$ relaxation processes (Table $S_{5}$ ). The obtained values for the Orbach relaxation barrier $(\Delta)$ were significantly smaller than expected from dcmagnetometry and NMR data, which is consistent with the data obtained previously for other Co(II)-based SMMs, where the magnetic relaxation was described using a combination of Raman and direct relaxation pathways with no Orbach contribution, ${ }^{25,}, 4-45$ or where the Orbach barrier was smaller than predicted by other methods. ${ }^{46-48}$

In conclusion, two new complexes are presented with $\mathrm{Co}(\mathrm{II})$ ions in a trigonal geometry intermediate between TP-TAP that reduces the large magnetic anisotropy observed in complexes with either of both geometries, verifying previously published predictions. The TAP geometry facilitates high magnetic anisotropy large contributions from non-Orbach relaxation mechanisms, suggesting the search for complexes with TP geometry. The elusive intermediate coordination polyhedron shown here is intriguing and worth studying. We are now exploring ways of enforcing or tuning it by introducing capping fragments to the pyridine moieties of $\mathrm{L}$ or modifying the bridging phenylene to vary the torsion at will.

\section{ASSOCIATED CONTENT}

\section{Supporting Information}

Synthesis, X-ray crystallography, magnetic measurements, NMR and theoretical calculations are in the SI. This material is available free of charge via the Internet at http://pubs.acs.org."

\section{Author Contributions}


All authors have given approval to the final version of the manuscript and contributed equally.

\section{ACKNOWLEDGMENT}

GA thanks the Generalitat de Catalunya for an ICREAAcademia 2018 Prize. Funding from Spanish MINECO through CTQ2015-68370-P (GA, MD, RD) and MAT201786826-R (OR) is acknowledged. We thank Advanced Light Source, a DOE Office of Science User Facility under contract DE-AC02-05CH11231. NMR was conducted with support from Russian Science Foundation (17-73-20369). The Center of molecular composition studies of INEOS RAS supported by Ministry of Science and Higher Education of the Russian Federation is acknowledged.

\section{REFERENCES}

1. Atanasov, M.; Aravena, D.; Suturina, E.; Bill, E.; Maganas, D.; Neese, F., First principles approach to the electronic structure, magnetic anisotropy and spin relaxation in mononuclear $3 \mathrm{~d}$-transition metal single molecule magnets Coord. Chem. Rev. 2015, 289, 177-214. 2. Frost, J. M.; Harriman, K. L.; Murugesu, M., The rise of 3 -d single-ion magnets in molecular magnetism: towards materials from molecules? Chem. Sci. 2016, 7, 2470-2491.

3. Sessoli, R.; Gatteschi, D.; Caneschi, A.; Novak, M., Magnetic bistability in a metal-ion cluster Nature 1993, 365, 141.

4. Sessoli, R.; Powell, A. K., Strategies towards single molecule magnets based on lanthanide ions Coord. Chem. Rev. 2009, 253, 2328-2341.

5. Winpenny, R. E., Quantum information processing using molecular nanomagnets as qubits Angew. Chem. Int. Ed. 20o8, 47, 79927994 .

6. Bogani, L.; Wernsdorfer, W., Molecular spintronics using singlemolecule magnets. In Nanoscience And Technology: A Collection of Reviews from Nature Journals, World Scientific: 2010; pp 194-201.

7. Aromí, G.; Brechin, E. K., Synthesis of 3d metallic singlemolecule magnets. In Single-molecule magnets and related phenomena, Springer: 2006; pp 1-67.

8. Liddle, S. T.; van Slageren, J., Improving f-element single molecule magnets Chem. Soc. Rev. 2015, 44, 6655-6669.

9. Goodwin, C. A.; Ortu, F.; Reta, D.; Chilton, N. F.; Mills, D. P., Molecular magnetic hysteresis at 60 kelvin in dysprosocenium $\mathrm{Na}$ ture 2017, 548, 439 .

10. Craig, G. A.; Murrie, M., 3d single-ion magnets Chem. Soc. Rev. 2015, 44, 2135-2147.

11. Liu, J.; Chen, Y.-C.; Liu, J.-L.; Vieru, V.; Ungur, L.; Jia, J.-H.; Chibotaru, L. F.; Lan, Y.; Wernsdorfer, W.; Gao, S., A stable pentagonal bipyramidal Dy (III) single-ion magnet with a record magnetization reversal barrier over $1000 \mathrm{~K}$ J. Am. Chem. Soc. 2016, 138, 54415450.

12. Chen, Y.-C.; Liu, J.-L.; Ungur, L.; Liu, J.; Li, Q.-W.; Wang, L.-F.; Ni, Z.-P.; Chibotaru, L. F.; Chen, X.-M.; Tong, M.-L., Symmetrysupported magnetic blocking at $20 \mathrm{~K}$ in pentagonal bipyramidal Dy (III) single-ion magnets J. Am. Chem. Soc. 2016, 138, $2829-2837$.

13. Gregson, M.; Chilton, N. F.; Ariciu, A.-M.; Tuna, F.; Crowe, I. F.; Lewis, W.; Blake, A. J.; Collison, D.; McInnes, E. J.; Winpenny, R. E., A monometallic lanthanide bis (methanediide) single molecule magnet with a large energy barrier and complex spin relaxation behaviour Chem. Sci. 2016, 7, 155-165.

14. Freedman, D. E.; Harman, W. H.; Harris, T. D.; Long, G. J.; Chang, C. J.; Long, J. R., Slow magnetic relaxation in a high-spin iron (II) complex J. Am. Chem. Soc. 2010, 132, 1224-1225.

15. Yao, X.-N.; Du, J.-Z.; Zhang, Y.-Q.; Leng, X.-B.; Yang, M.-W.; Jiang, S.-D.; Wang, Z.-X.; Ouyang, Z.-W.; Deng, L.; Wang, B.-W., Two-coordinate Co (II) imido complexes as outstanding singlemolecule magnets J. Am. Chem. Soc. 2o16, 139, 373-380.

16. Rechkemmer, Y.; Breitgoff, F. D.; Van Der Meer, M.; Atanasov, M.; Hakl, M.; Orlita, M.; Neugebauer, P.; Neese, F.; Sarkar, B.; Van
Slageren, J., A four-coordinate cobalt (II) single-ion magnet with coercivity and a very high energy barrier Nature Commun. 2016, 7 , 10467 .

17. Novikov, V. V.; Pavlov, A. A.; Nelyubina, Y. V.; Boulon, M.-E.; Varzatskii, O. A.; Voloshin, Y. Z.; Winpenny, R. E., A trigonal prismatic mononuclear cobalt (II) complex showing single-molecule magnet behavior J. Am. Chem. Soc. 2015, 137, 9792-9795.

18. Pavlov, A. A.; Nelyubina, Y. V.; Kats, S. V.; Penkova, L. V.; Efimov, N. N.; Dmitrienko, A. O.; Vologzhanina, A. V.; Belov, A. S.; Voloshin, Y. Z.; Novikov, V. V., Polymorphism in a cobalt-based single-ion magnet tuning its barrier to magnetization relaxation The journal of physical chemistry letters 2016, 7, 4111-4116.

19. Bunting, P. C.; Atanasov, M.; Damgaard-Møller, E.; Perfetti, M.; Crassee, I.; Orlita, M.; Overgaard, J.; Van Slageren, J.; Neese, F.; Long, J. R., A linear cobalt (II) complex with maximal orbital angular momentum from a non-Aufbau ground state Science 2018, 362, eaat7319. 2o. Meng, Y.-S.; Mo, Z.; Wang, B.-W.; Zhang, Y.-Q.; Deng, L.; Gao, S., Observation of the single-ion magnet behavior of $\mathrm{d} 8$ ions on twocoordinate Co (I)-NHC complexes Chem. Sci. 2015, 6, 7156-7162.

21. Zadrozny, J. M.; Xiao, D. J.; Atanasov, M.; Long, G. J.; Grandjean, F.; Neese, F.; Long, J. R., Magnetic blocking in a linear iron (I) complex Nature Chem. 2013, 5, 577.

22. Zadrozny, J. M.; Atanasov, M.; Bryan, A. M.; Lin, C.-Y.; Rekken, B. D.; Power, P. P.; Neese, F.; Long, J. R., Slow magnetization dynamics in a series of two-coordinate iron (II) complexes Chem. Sci. 2013, 4, 125-138.

23. Zhu, Y.-Y.; Cui, C.; Zhang, Y.-Q.; Jia, J.-H.; Guo, X.; Gao, C.; Qian, K.; Jiang, S.-D.; Wang, B.-W.; Wang, Z.-M., Zero-field slow magnetic relaxation from single $C_{0}$ (II) ion: a transition metal single-molecule magnet with high anisotropy barrier Chem. Sci. 2013, 4, 1802-18o6.

24. Pavlov, A. A.; Savkina, S. A.; Belov, A. S.; Nelyubina, Y. V.; Efimov, N. N.; Voloshin, Y. Z.; Novikov, V. V., Trigonal Prismatic Tris-pyridineoximate Transition Metal Complexes: A Cobalt (II) Compound with High Magnetic Anisotropy Inorg. Chem. 2017, 56, 6943-6951.

25. Pavlov, A. A.; Aleshin, D.; Savkina, S.; Belov, A.; Efimov, N.; Nehrkorn, J.; Ozerov, M.; Voloshin, Y.; Nelyubina, Y.; Novikov, V., A trigonal prismatic cobalt (II) complex as a single molecule magnet with a reduced contribution from quantum tunneling ChemPhysChem 2019, 10.1002/cphc.201900219.

26. Novikov, V. V.; Ananyev, I. V.; Pavlov, A. A.; Fedin, M. V.; Lyssenko, K. A.; Voloshin, Y. Z., Spin-crossover anticooperativity induced by weak intermolecular interactions The journal of physical chemistry letters 2014, 5, 496-500.

27. Churchill, M. R.; Gold, K.; Maw Jr, C. E., Crystal structure and molecular geometry of bis [hydrotris (1-pyrazolyl) borato] cobalt (II) Inorg. Chem. 1970, 9, 1597-1604.

28. Zhang, Y.-Z.; Gómez-Coca, S.; Brown, A. J.; Saber, M. R.; Zhang, X.; Dunbar, K. R., Trigonal antiprismatic Co (II) single molecule magnets with large uniaxial anisotropies: importance of Raman and tunneling mechanisms Chem. Sci. 2o16, 7, 6519-6527.

29. Villa-Pérez, C.; Oyarzabal, I.; Echeverría, G. A.; Valencia-Uribe, G. C.; Seco, J. M.; Soria, D. B., Single-Ion Magnets Based on Mononuclear Cobalt (II) Complexes with Sulfadiazine Eur. J. Inorg. Chem. 2016, 2016, 4835-4841.

3o. Li, J.; Han, Y.; Cao, F.; Wei, R.-M.; Zhang, Y.-Q.; Song, Y., Two field-induced slow magnetic relaxation processes in a mononuclear Co (II) complex with a distorted octahedral geometry Dalton Trans. 2016, 45, 9279-9284.

31. Zhang, J.; Li, J.; Yang, L.; Yuan, C.; Zhang, Y.-Q.; Song, Y., Magnetic anisotropy from trigonal prismatic to trigonal antiprismatic $\mathrm{Co}$ (II) complexes: experimental observation and theoretical prediction Inorg. Chem. 2018, 57, 3903-3912.

32. Ozumerzifon, T. J.; Bhowmick, I.; Spaller, W. C.; Rappé, A. K.; Shores, M. P., Toward steric control of guest binding modality: a cationic Co (II) complex exhibiting cation binding and zero-field relaxation Chem. Commun. 2017, 53, 4211-4214.

33. Darawsheh, M.; Barrios, L. A.; Roubeau, O.; Teat, S. J.; Aromí, G., Guest-, Light-and Thermally-Modulated Spin Crossover in [FeII2] Supramolecular Helicates Chemistry- $A$ European Journal 2016, 22, $8635-8645$. 
34. Darawsheh, M.; Barrios, L.; Roubeau, O.; Teat, S.; Aromí, G., Guest-tuned spin crossover in flexible supramolecular assemblies templated by a halide ( $\mathrm{Cl}-$, $\mathrm{Br}-$ or I-) Chem. Commun. 2017, 53, 569572.

35. Lodi Rizzini, A.; Krull, C.; Balashov, T.; Mugarza, A.; Nistor, C.; Yakhou, F.; Sessi, V.; Klyatskaya, S.; Ruben, M.; Stepanow, S., Exchange biasing single molecule magnets: coupling of TbPc2 to antiferromagnetic layers Nano Lett. 2012, 12, 5703-5707.

36. Hiller, M.; Krieg, S.; Ishikawa, N.; Enders, M., Ligand-Field Energy Splitting in Lanthanide-Based Single-Molecule Magnets by NMR Spectroscopy Inorg. Chem. 2017, 56, 15285-15294.

37. Morita, T.; Damjanović, M.; Katoh, K.; Kitagawa, Y.; Yasuda, N.; Lan, Y.; Wernsdorfer, W.; Breedlove, B. K.; Enders, M.; Yamashita, M., Comparison of the Magnetic Anisotropy and Spin Relaxation Phenomenon of Dinuclear Terbium (III) Phthalocyaninato SingleMolecule Magnets Using the Geometric Spin Arrangement J. Am. Chem. Soc. 2018, 140, 2995-3007.

38. Pavlov, A. A.; Nehrkorn, J.; Pankratova, Y.; Ozerov, M.; Mikhalyova, E. A.; Polezhaev, A.; Nelyubina, Y. V.; Novikov, V. V., Detailed electronic structure of a high-spin cobalt (II) complex determined from NMR and THz-EPR spectroscopy Phys. Chem. Chem. Phys. 2019, 10.1039/C9CPo1474H.

39. Hansen, S.; Müller-Warmuth, W., J. R. Pilbrow: Transition Ion Electron Paramagnetic Resonance, Clarendon Press, Oxford 1990. ISBN o-19-855214-9. 717 Seiten, Preis: $₫ 85 .-$ Berichte der Bunsengesellschaft für physikalische Chemie 1991, 95, 1307-1307.

40. Myers, W. K.; Duesler, E. N.; Tierney, D. L., Integrated Paramagnetic Resonance of High-Spin Co (II) in Axial Symmetry: Chemical Separation of Dipolar and Contact Electron- Nuclear Couplings Inorg. Chem. 2008, 47, 6701-6710.

41. Myers, W. K.; Scholes, C. P.; Tierney, D. L., Anisotropic Fermi Couplings Due to Large Unquenched Orbital Angular Momentum: Q-Band ${ }_{1} \mathrm{H},{ }_{14} \mathrm{~N}$, and ${ }_{11 \mathrm{~B}}$ ENDOR of Bis (trispyrazolylborate) Cobalt (II) J. Am. Chem. Soc. 2009, 131, 10421-10429.

42. Marts, A. R.; Greer, S. M.; Whitehead, D. R.; Woodruff, T. M.; Breece, R. M.; Shim, S. W.; Oseback, S. N.; Papish, E. T.; Jacobsen, F. E.; Cohen, S. M., Dual mode EPR studies of a Kramers ion: High-spin Co (II) in 4-, 5-and 6-coordination Appl. Magn. Reson. 2011, 40, 501511.

43. Abragam, A.; Bleaney, B., Electron paramagnetic resonance of transition ions. OUP Oxford: 2012.

44. Gómez-Coca, S.; Urtizberea, A.; Cremades, E.; Alonso, P. J.; Camón, A.; Ruiz, E.; Luis, F., Origin of slow magnetic relaxation in Kramers ions with non-uniaxial anisotropy Nature Commun. 2014, 5, 4300.

45. Lunghi, A.; Totti, F.; Sessoli, R.; Sanvito, S., The role of anharmonic phonons in under-barrier spin relaxation of single molecule magnets Nature Commun. 2017, 8, 14620.

46. Colacio, E.; Ruiz, J.; Ruiz, E.; Cremades, E.; Krzystek, J.; Carretta, S.; Cano, J.; Guidi, T.; Wernsdorfer, W.; Brechin, E. K., Slow Magnetic Relaxation in a CoII-YIII Single-Ion Magnet with Positive Axial ZeroField Splitting Angew. Chem. Int. Ed. 2013, 52, 9130-9134.

47. Huang, X.-C.; Zhou, C.; Shao, D.; Wang, X.-Y., Field-induced slow magnetic relaxation in cobalt (II) compounds with pentagonal bipyramid geometry Inorg. Chem. 2o14, 53, 12671-12673.

48. Zhu, Y.-Y.; Zhu, M.-S.; Yin, T.-T.; Meng, Y.-S.; Wu, Z.-Q.; Zhang, Y.-Q.; Gao, S., Cobalt (II) coordination polymer exhibiting singleion-magnet-type field-induced slow relaxation behavior Inorg. Chem. 2015, 54, 3716-3718. 
SYNOPSIS TOC The new supramolecular coordination helicates $\left(\mathrm{Cl} @\left[\mathrm{Co}_{2} \mathrm{~L}_{3}\right]\right)^{3+}$ and $\left(\mathrm{Cl} @\left[\mathrm{CoZnL}_{3}\right]\right)^{3^{+}}$contain $\mathrm{Co}(\mathrm{II})$ ions in a coordinate geometry in between trigonal prism (TP) and antiprism (TAP). A combination of solid state and solution magnetic studies unveil the slow relaxation of the magnetization of these ions, despite the low axial magneto-anisotropy, here detected as previously predicted for this geometry.

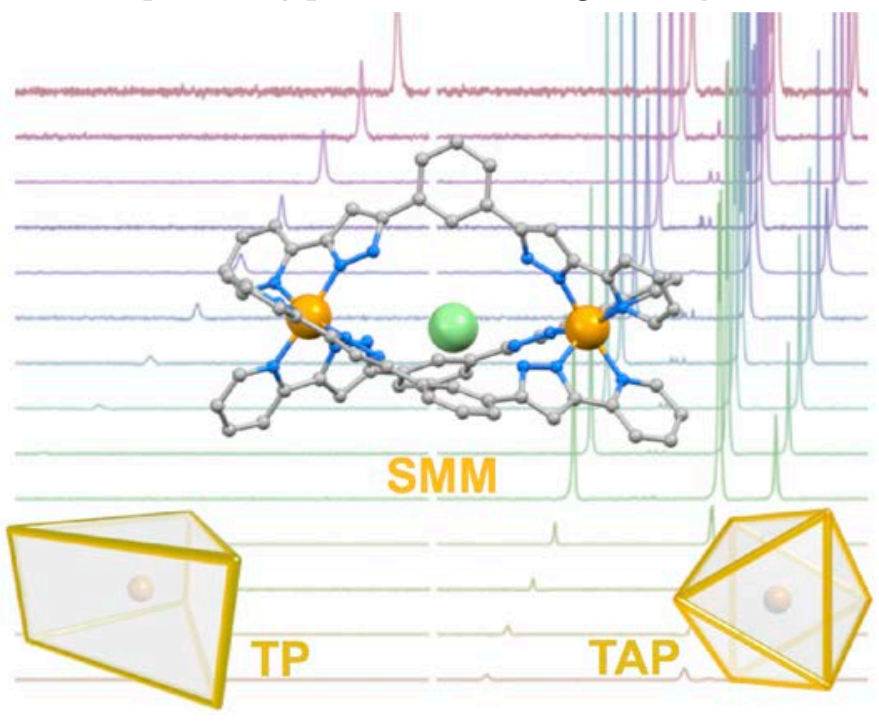

